\title{
The clouded leopard in Malaysian Borneo
}

\author{
Alan Rabinowitz, Patrick Andau and Paul P. K. Chai
}

The clouded leopard Neofelis nebulosa has already disappeared from part of its range in southern Asia; it is classified as vulnerable by IUCN and is on Appendix I of CITES. Little is known about this secretive forest-dweller anywhere in its range, and the sparse information needs to be augmented so that effective conservation measures may be taken if necessary. In early 1986 the senior author travelled through the interior of Malaysian Borneo, staying at villages and timber camps, to assess the status of the species in the region and to find out more about its behaviour.

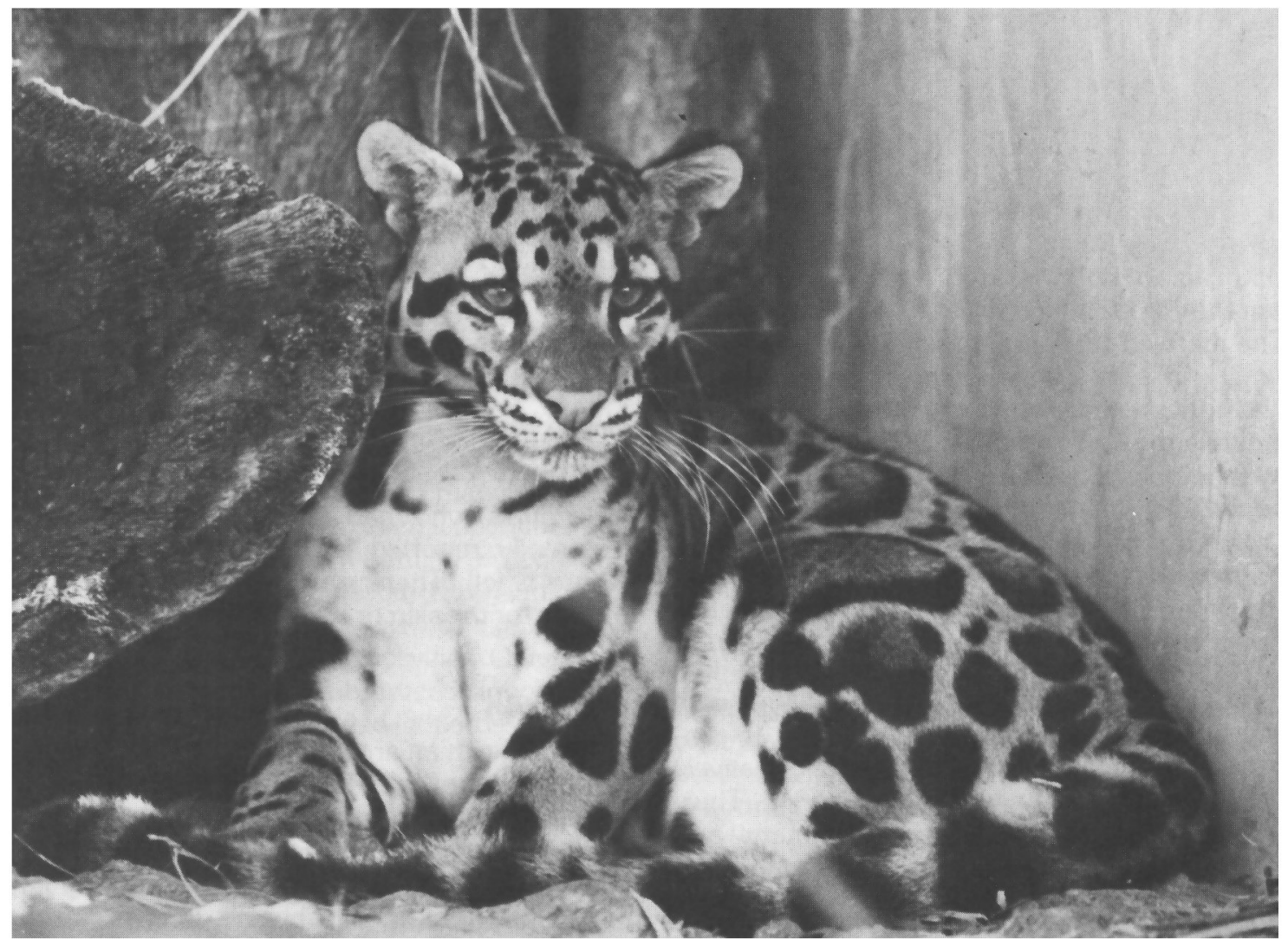

Clouded leopard in captivity in Thailand (Alan Rabinowitz). 
The clouded leopard is one of the most elusive of the larger felids in Asian forests. With body characteristics that fall between those of large and small cats, it has upper canines that are relatively longer than in any other living felid (Guggisberg, 1975). These tusk-like canines have a sharp posterior edge, which caused Sterndale (1884) to compare the clouded leopard to the extinct sabre-toothed tiger.

Occurring over an extensive area of southern Asia, the clouded leopard is the largest wild felid on the island of Borneo. Due to its secretive and solitary habits, however, this cat is seldom observed, and much of the knowledge concerning its ecology remains anecdotal. Between 15 January and 15 March 1986 the senior author travelled through the Malaysian states of Sabah and Sarawak in northern and western Borneo to assess the current status of the clouded leopard in that region and to learn something of its behaviour. Since its presence is usually detected only by pugmarks or chance sightings, the primary means of data collection involved interviews with local residents, timber workers and forestry officials for information regarding the cat's whereabouts and habits. Only first-hand sightings or pugmarks were considered reliable data. Photographs and colour drawings of the wild cats found in Borneo (Payne et al., 1985) were used during interviews to avoid confusion. The marbled cat Felis marmota, smaller but very similar in appearance to the clouded leopard, was often mistaken for that species. If an individual could not distinguish between these two species, their information was not used in this paper.

\section{Sabah}

Encompassing approximately 76,000 sq km, Sabah is the second largest of the 13 Malaysian states. Most of the State's population is concentrated in coastal towns and villages; relatively few villages are situated in the interior. Thus, extensive areas of remaining primary and secondary forests continue to support an abundant and diverse wild fauna.

Of 90 first-hand sightings or other signs of clouded leopards recorded throughout the State, 108

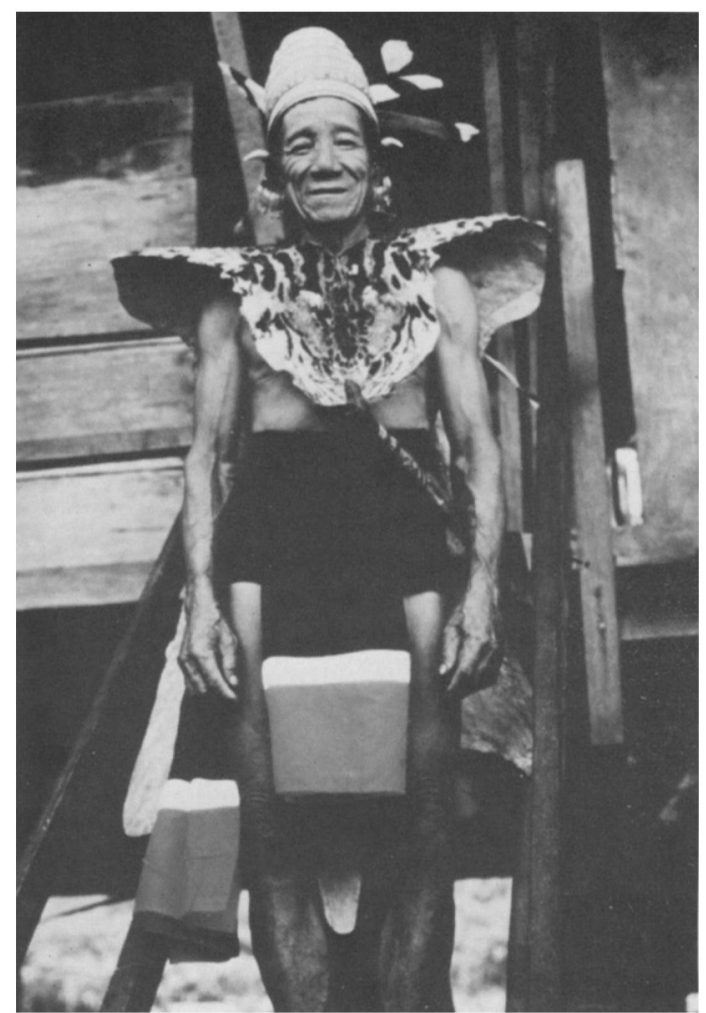

Native tribesman in Sarawak wearing a clouded leopard ceremonial coat (Michael Kavanagh).

25 per cent occurred within the previous year, indicating that this cat is still present in some numbers in the surrounding forests. Although hunters often reported shooting clouded leopards on sight, the animals are neither frequently encountered nor specifically hunted. Individuals who had killed clouded leopards frequently reported leaving the entire carcass where it fell. There seemed to be virtually no market for the skin or body parts.

\section{Sarawak}

Sarawak, with an area of nearly $125,000 \mathrm{sq} \mathrm{km}$, is the largest of the Malaysian states, but with a very different demography from that of Sabah. The people of Sarawak are over 80 per cent rural (Chan et al., 1985) with a diverse array of indigenous groups, which have long occupied the interior. A history of hunting throughout Sarawak has affected the distribution and

Oryx Vol 21 No 2. April 1987 
abundance of particular species of wildlife throughout the state (Caldecott, 1986).

In the past, the clouded leopard was much sought after in Sarawak by many native tribes. Their canine teeth were used as ear ornaments and their skins as ceremonial coats or seating mats (Gibson-Hill, 1950; Shelford, 1985). However, in recent years several factors have severely curtailed the hunting of this cat. Laws restricting the killing of clouded leopards or the selling of their body parts have had an effect in the market place. There also appears to be a shift by the younger men away from hunting and many traditional practices of the past. Most of the young men interviewed said that they never did any serious or regular hunting, and none of them had ever seen a clouded leopard. The older native men said that they did much less hunting now than in their youth. They often claimed that good forest with abundant wildlife was now too far away from their longhouses to make hunting worthwhile.

Since dogs are commonly used by hunters in the interior to chase wildlife, particularly bearded pigs Sus barbatus, most clouded leopard encounters involved dogs inadvertently chasing a clouded leopard into a tree or bringing the animal to bay. Of 71 sightings of clouded leopards reported during this survey in Sarawak, 37 per cent of them had occurred within the previous year. As in Sabah, this figure indicates that these cats are still present in some numbers. There were no recent reports of hunters specifically going after these cats, and many said that they would not shoot them even if encountered. A recent detailed survey of hunting in 220 communities in Sarawak (Caldecott, 1986) indicated that the clouded leopard was not significantly affected by present hunting activities. Only 1 per cent of trophies and pets observed in longhouses and bazaars involved clouded leopards.

There were four first-hand reports during this survey (three in Sarawak and one in Sabah) of large black cats sighted in the wild. Davies and Payne (1982) reported six such sightings during their survey in Sabah. It is possible that there exists a black phase of the clouded leopard similar to that of the panther Panthera pardus.

Clouded leopard in Malaysian Bomeo

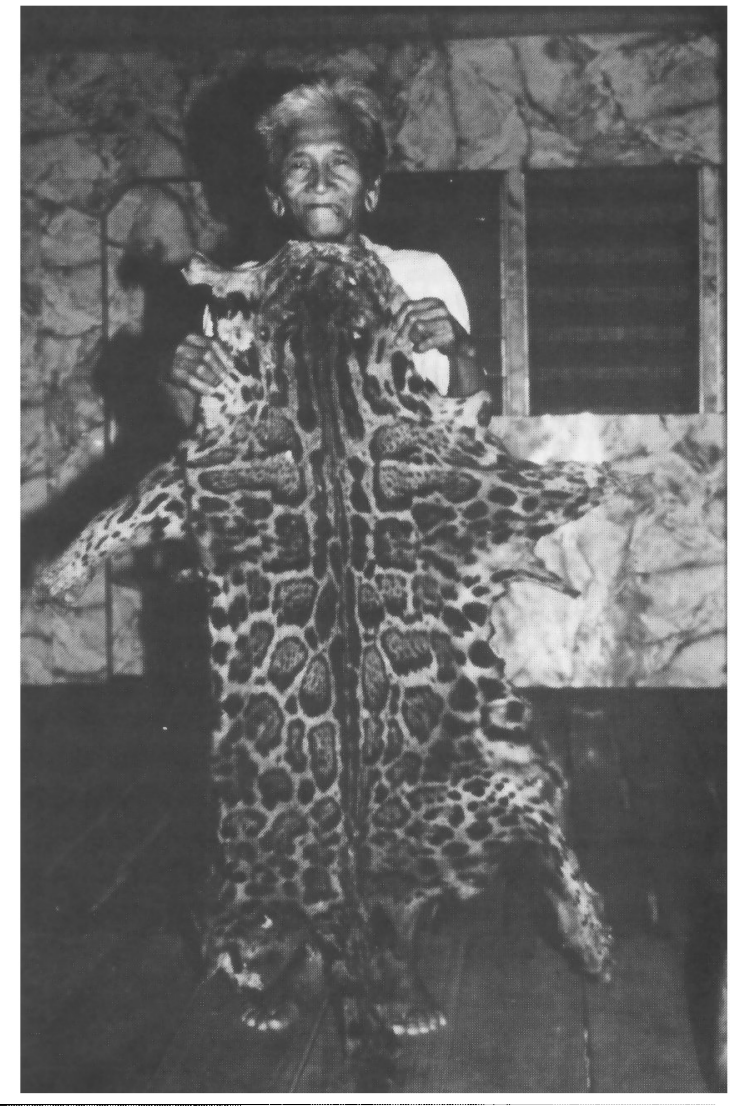

Iban tribesman in Sarawak holding clouded leopard skin used as a floor mat (Alan Rabinowitz).

\section{Clouded leopard behaviour}

Early accounts describe the clouded leopard as a rarely seen, arboreal, nocturnal cat believed to exist on a diet primarily of deer and birds (Raffles, 1821; Swinhoe, 1862). The Malaysian term for clouded leopard, harimau-dahan, meaning branch-tiger, suggests that the cats have arboreal habits. Selous and Banks (1935) questioned these assumptions on the basis of personal experience involving their hunting dogs chasing these cats on the ground and bringing them to bay during the daytime. They speculated that the clouded leopard is more terrestrial and less nocturnal than previously assumed.

During this survey, 82 per cent of the sightings of clouded leopards in Sabah and Sarawak involved the cats travelling on the ground, 
usually along roads or trails through either primary or secondary (selectively logged) forest. Of those observed in trees, 75 per cent were seen during the daytime (07.00-19.00 hours) and all but two were in primary forest. Sightings of clouded leopards occurred from sea level up to $1273 \mathrm{~m}$ in the Crocker Range, Sabah.

These observations indicate certain behavioural attributes of this cat. The fact that clouded leopards are often seen walking along roads and trails indicates that they use this limited resource for travel and possibly hunting, as has been observed in other large cats (Schaller, 1967; Sunquist, 1981; Rabinowitz and Nottingham, 1986). These data also support the assumption of Selous and Banks (1935) that clouded leopards probably spend a large portion of their waking hours moving on the ground, during both day and night. Such flexibility in activity allows a top predator to optimize access to food resources.

The clouded leopard is not arboreal in the true sense of the word, and trees are probably used primarily as resting sites. Resting sites above the ground may be particularly important in the Asian forests due to the omnipresent terrestrial leeches ready to take advantage of any warmblooded meal. Large numbers of leeches could cause significant blood loss to an animal and allow potential secondary infections from the wounds they create (Smythies, 1959). In steep, rocky areas lacking tall trees, clouded leopards were observed on several occasions sleeping on top of large boulders.

Although tall trees may be favoured by clouded leopards where they occur, the lack of primary forest does not appear to restrict the activities of these cats. They are often seen in selectively logged forest from which most tall trees have been extracted and where there is no primary forest nearby. This does not indicate, however, the way in which changes in forest structure affect the cat's behaviour patterns. Prey availability is probably a major factor influencing where the clouded leopard is to be found. Although selective logging severely disturbs certain species within the forest, other species can quickly recover and continue to maintain viable populations. Top carnivores, such as large cats, 110 appear to be maintained in logged forest in the absence of hunting (Johns, 1985).

There was no evidence in this study, nor in the survey by Davies and Payne (1982), to indicate marking behaviour by clouded leopards in the form of scrapes and/or obvious faecal deposits along roads or trails where the cats were known to travel. Such behaviour is well documented in other large solitary cats (Schaller, 1967; Sunquist, 1981; Rabinowitz and Nottingham, 1986). In areas with small or isolated populations, cats may simply be able to avoid each other without advertising their presence through behaviour such as marking (Schaller and Crawshaw, 1980). This could be the case with the clouded leopard in Borneo. The number of recent sightings documented in this study indicates that the clouded leopard is present throughout large areas of continuous primary or secondary forest. It may occur, however, in relatively low population densities since it never appeared to be abundant or frequently encountered in any one area. Whether this is a natural phenomenon or a result of disturbances to the forest needs further investigation.

Reports of clouded leopards with kills indicated that their diet in Borneo includes at least the following wild species: sambar deer Cervus unicolor, barking deer Muntiacus muntjac, mouse deer Tragulus spp., bearded pig, common palm civet Paradoxurus hermaphroditus, grey leaf monkey Presbytis hosei, fish and porcupine. Three reports of clouded leopard killing livestock (cattle and chickens) indicate that they occasionally take domestic animals, but they were not considered by local residents to be pests. On two occasions hunters reported examining clouded leopard kills (a barking deer and a bearded pig). In both cases the animals appeared to have been killed by puncture wounds in the back of the neck.

At present, the clouded leopard still appears to inhabit many areas throughout Malaysian Borneo and seems to be in no imminent danger of extinction. However, it is nowhere abundant, and might exist in relatively low population densities. With current deforestation and logging trends, the status of this cat may change in the near future. Having already been extirpated from

Oryx Vol 21 No 2. April 1987 
some areas of its former range, detailed research needs to be conducted on this rare, secretive cat before it is no longer seen at all. With knowledge concerning this cat's ecological needs and the effect of selective logging on its behaviour, we can begin to devise habitat and minimum area requirements to ensure the future survival of this species.

\section{Acknowledgments}

Wildlife Conservation International of The New York Zoological Society and Mr Edwin Gould sponsored this survey. We would also like to express our appreciation to the various government officials and workers in Sabah and Sarawak that assisted in the field, and to Dr Archie Carr III, Dr Elizabeth Bennett, Dr John Payne, and Dr Julian Caldecott for critical review of the manuscript.

\section{References}

Caldecott, J.O. 1986. Hunting and Wildlife Management in Sarawak. World Wildlife Fund Malaysia, Kuala Lumpur.

Chan, L., Kavanagh, M., Cranbrook, Earl of, Langub, J. and Wells, D. 1985. Conservation Strategy Malaysia: Proposals for a Conservation Strategy for Sarawak. World Wildlife Fund Malaysia, Kuala Lumpur.

Davies, A.G. and Payne, J.B. 1982. A Faunal Survey of Sabah. World Wildlife Fund Malaysia, Kuala Lumpur.

Gibson-Hill, C.A. 1950. Notes on the clouded leopard [Neofelis nebulosa (Griffith)]. J. Bombay Nat. History Society, 49 (3), 543-546.

Guggisberg, C.A.W. 1975. Wild Cats of the World. Taplinger Publ. Co., New York.
Johns, A.D. 1985. Selective logging and wildlife conservation in tropical rainforest: problems and recommendations. Biol. Conserv. 31, 355-375.

Payne, J., Francis, C. and Phillips, K. 1985. A Field Guide to the Mammals of Bomeo. The Sabah Society, Malaysia.

Rabinowitz, A. and Nottingham, B. 1986. Ecology and behavior of the jaguar (Panthera onca). In Belize, Central America, Part I, p. 210. Journal of Zoology, London.

Raffles, S. 1821. Descriptive catalogue of a zoological collection made in Sumatra. Trans. Linn. Soc. Lond., 13 (1), 239-274.

Schaller, G. 1967. The Deer and the Tiger: a Study of Wildlife in India. University of Chicago Press, Chicago.

Schaller, G. and Crawshaw, P.G. 1980. Movement patterns of jaguar. Biotropica, 12, 161-168.

Selous, E.M. and Banks, E. 1935. The clouded leopard in Sarawak. Sarawak Mus. J. 4 (3), 263-266.

Shelford, R.W. 1985. A Naturalist in Borneo. Oxford University Press, Oxford.

Smythies, B.E. 1959. Leeches of Borneo. Sarawak Museum J. 9 (13-14), 279-294.

Sterndale, R.A. 1884. Natural History of Mammals of India and Ceylon. Thacker, Spink and Co., Calcutta.

Sunquist, M.E. 1981. The social organization of tigers (Panthera tigris) in Royal Chitawan National Park, Nepal. Smithsonian Contributions to Zoology, No. 336.

Swinhoe, R. 1862. On the mammals of the island of Formosa (China). Proc. Zool. Soc. London, 23, 347-365.

Dr Alan Rabinowitz, Wildlife Conservation International, New York Zoological Society, Bronx, NY 10460, USA.

Mr Patrick Andau, Game Branch, Sabah Forest Dept., PO Box 311, Sandakan, Sabah.

Dr PaulP. K. Chai, National Parks and Wildlife Office, Forest Dept., Jalan Gartak, Kuching, Sarawak.

\section{Acronyms and abbreviations used in this issue of Oryx}

$\mathrm{BBC}$

British Broadcasting Corporation

CITES

Convention on Trade in

Endangered Species of Wild

Fauna and Flora

CNPPA

Commission on Parks and

Protected Areas

EEC

European Economic Community

ICBP
International Council for Bird Preservation
IUCN

International Union for Conservation of Nature and Natural Resources

NNR

NCC

UNESCO

WFT

WWF
National Nature Reserve

Nature Conservancy Council

United Nations Educational,

Scientific, and Cultural

Organization

Wildlife Fund Thailand

World Wildlife Fund 